\title{
'You've got dry macular degeneration, end of story': a qualitative study into the experience of living with non-neovascular age-related macular degeneration
}

\author{
Deanna J. Taylor ${ }^{1} \cdot$ Lee Jones ${ }^{1} \cdot$ Alison M. Binns ${ }^{1} \cdot$ David P. Crabb ${ }^{1}$ \\ Received: 16 November 2018 / Revised: 25 March 2019 / Accepted: 4 April 2019 / Published online: 22 May 2019 \\ (c) The Author(s) 2019. This article is published with open access
}

\begin{abstract}
Background/objectives To investigate the impact of non-neovascular (dry) age-related macular degeneration (AMD) on the person with respect to diagnosis, vision loss and coping strategies.

Subjects/methods Volunteers with dry AMD with a range of disease severity were given an eye examination and asked to describe aspects of their experience with dry AMD in a semi-structured interview. Interviews were audio-recorded, transcribed, and subjected to Framework analysis. Overarching themes were pre-defined, whilst subthemes were derived from the data.

Results Twenty-seven participants ( $81 \%$ female), with early $(n=3)$, intermediate $(n=16)$ and advanced dry AMD (GA; $n=8$ ) were interviewed. Median (interquartile range) age (years), logMAR binocular visual acuity and Pelli-Robson contrast sensitivity were $76(71,80), 0.2(0.18,0.40)$ and $1.65(1.35,1.93)$, respectively. Overarching themes (and subthemes) were: diagnosis (relationship with healthcare professional, psychological impact of diagnosis, and knowledge of AMD, both pre- and post-diagnosis), impact of visual loss (functional and psychological) and coping strategies (help from others and personal strategies). Many participants reported feelings of distress at the time of diagnosis and, particularly noteworthy, several reported a constant fear of their condition worsening.

Conclusions Dry AMD, for which there is currently no treatment, can have a significant impact on individuals, even in its early stages, before significant functional vision loss is manifest, as well as in its intermediate and advanced stages. Results from this study offer important insight into the experience of living with dry AMD not previously explored. Moreover, the results have the potential to serve as an educational resource for eyecare professionals.
\end{abstract}

\section{Introduction}

Non-neovascular, or dry age-related macular degeneration (AMD) is a gradually progressive, incurable, sightthreatening condition. Whilst several studies have investigated the impact of living with other eye conditions, including neovascular AMD (nAMD) [1, 2], the impact of

Supplementary information The online version of this article (https:// doi.org/10.1038/s41433-019-0445-8) contains supplementary material, which is available to authorized users.

$\triangle$ David P. Crabb

David.Crabb.1@city.ac.uk

1 Division of Optometry and Visual Science, School of Health Sciences, City, University of London, Northampton Square, London EC1V 0HB, UK living with dry AMD remains relatively neglected in the literature. Effects of dry AMD on performance of activities of daily living are now becoming better appreciated through both patient-reported outcome measures and performancebased studies [3]. However, a more explorative approach to understanding the experience of people living with a condition is through qualitative methods [4]. Qualitative research has potential to add important knowledge as well as shape future research and practice [5-8]. Yet studies adopting qualitative methodologies are underrepresented in ophthalmology journals [9].

Our recent systematic review [3] evidenced the scarcity of qualitative research focusing on the patient experience of AMD [10-20]. Moreover, only two studies [10, 11] reported specifically on participants with dry AMD. Of these, one [10] had only six participants with dry AMD and two of the four themes identified in the results related only to participants with nAMD. The other [11] reports just one case 
study of a person living with nAMD and their partner living with dry AMD.

Onset of visual impairment in nAMD tends to be sudden whereas that of dry AMD is more gradual. In most cases, vision in wet AMD may be maintained or improved with use of intra-vitreal anti-VEGF injections, whilst dry AMD remains untreatable. As such, the patient experience in dry AMD differs from that of wet AMD. For example, previous qualitative research [10] reports optimism amongst patients whose nAMD allows them to be treated although the invasive nature of nAMD treatment may be associated with negative effects on quality of life [2, 10]. Furthermore, the insidious nature of dry AMD means that diagnosis may occur before the patient is aware of any visual disturbances. We suggest that this may have a psychological impact on the patient which differs to that of nAMD. We propose that the patient journey in dry AMD is unique and worthy of further investigation; this is therefore the subject of this study.

We aim to explore the patient experience of dry AMD, with particular emphasis on diagnosis and impact on everyday life of the condition as well as coping strategies developed.

\section{Methods}

\section{Participant recruitment, baseline clinical examination, and ethical approval}

People with dry AMD were recruited from Moorfields Eye Hospital Trust, London, optometrists local to the study institution and the membership of the Macular Society (www.macularsociety.org). Participants were required to be aged $\geq 60$ years, have sufficiently clear ocular media, adequate pupillary dilation and fixation to allow quality fundus imaging (Lens Opacities Classification System (LOCS) III grading scale [21] of grade $<3$ ), and to have dry AMD in their better-seeing eye. Fellow eyes were permitted to be of any AMD status because the impact of the better-seeing eye has been found to have a stronger relationship with visionrelated quality of life than the worse-seeing eye [22-24]. Binocular VA was required to be $\log$ MAR 0.7 or better (Snellen equivalent of 6/30) as measured using an Early Treatment Diabetic Retinopathy Study (ETDRS) chart. Participants were excluded if they had nAMD in their better-seeing eye, ocular or systemic diseases other than AMD that could affect visual function or history of medication known to affect macular function, or high risk of angle closure during pupillary dilation (Van Herick $<$ Grade 2 , history of angle closure or experience of prodromal symptoms of angle closure). In addition, participants were required to pass an abridged version of the Mini Mental
State Evaluation [25] which has been used in previous vision science research [26, 27] and to have sufficient knowledge of the English language to understand the Participant Information Sheet and carry out a semi-structured interview with the researcher.

The study was approved by Nottingham 2 National Health Service (NHS) Research Ethics Committee (15/EM/ 0063) and was conducted according to the tenets of the Declaration of Helsinki. Written, informed consent was obtained from each participant prior to examination. Participant information was anonymised before being entered into a secure computer database.

After providing informed consent, participants underwent baseline examinations to evaluate their AMD status and to ensure eligibility for participation. Structured history and symptoms were taken to assess general health. Best-corrected visual acuity (VA) was recorded using the ETDRS chart. This was scored per letter (and in logMAR format) and participants were encouraged to read down the chart until they were unable to read three out of a possible five letters on a line. Contrast sensitivity (CS) was tested with the Pelli-Robson chart at $1 \mathrm{~m}$ (binocularly) with best-corrected distance prescription. This was scored per letter (if participants read ' $\mathrm{C}$ ' instead of ' $\mathrm{O}$ ' or vice versa this was counted as correct).

Following the interview, participants underwent dilated fundus examination. Lens clarity (LOCS III) [15] and anterior chamber angle (Van Herick) were graded using the slit lamp biomicroscope. Digital colour fundus photographs were obtained and these were used to classify and grade AMD status by the better-seeing eye (determined by VA) as early, intermediate, or advanced according to the Beckman classification scale [30]. This widely used scale grades macular disease status according to drusen size, pigmentary abnormalities, and presence or absence of geographic atrophy (GA) or nAMD. Spectral-domain optical coherence tomography and fundus autofluorescence images were taken using a Spectralis (Heidelberg Engineering, Heidelberg, Germany).

\section{Interview procedure}

Semi-structured interviews were conducted and audiorecorded between May 2015 and February 2016. Interviews were based on a topic guide (see Supplementary File 1) that was written prior to the start of the study. Topic guide questions were initially based on their previous use [6], adapted to the current study aims, and refined further after an initial pilot interview. Interview questions were open ended and asked in such a way that required minimal interviewer input and encouraged detailed responses from participants. Care was taken not to ask leading questions, although prompts were used to encourage participants to 
expand on a point, or to clarify a question where it appeared that the participant may have misunderstood the interviewer. Efforts were made to ensure that participants were describing experiences relating to their corrected vision; i.e. when wearing their refractive correction. It was emphasised prior to the interview that there were no right or wrong answers and that participants would be given the opportunity to expand on or clarify any points at the end of the interview.

All interviews were conducted in person at City, University of London by the lead author (a female optometrist; DJT). The majority of interviews were conducted in a study room, with only the participant and researcher present, but a small number of participants chose to have a friend or family member present in the room. The researcher corresponded with participants via email and telephone during the recruitment process but had never met them in person before the study visit. Participants' travel expenses were reimbursed. The study followed the Consolidated Criteria for Reporting Qualitative Research (COREQ) [28].

\section{Analysis}

Transcribed data were analysed by one of the authors (DJT) using Framework analysis [29]. Transcripts were read and reread, themes were identified, and example quotes were chosen to illustrate these themes. Overarching themes were defined by the study aims, whilst subthemes were derived from the data. A second researcher (LJ) independently read and analysed a subset $(20 \%)$ of the transcripts, and reviewed the completed Framework chart. Any differences of opinion regarding meaning of sentences or importance of themes were discussed until a consensus was reached. The qualitative software package NVIVO V.11 (QSR International, Cambridge, Massachusetts, USA) was used for data management.

The themes emerging from the interviews are illustrated with direct quotes from the transcripts, which are presented in italicised font. Each quotation is followed by a code where the first initial represents AMD stage $(\mathrm{E}=$ Early, $\mathrm{I}=$ Intermediate, $\mathrm{A}=$ Advanced) and the second initial represents gender $(\mathrm{F}=$ Female, $\mathrm{M}=$ Male $)$.

\section{Results}

\section{Participants}

Twenty-seven participants ( $81 \%$ female) were interviewed. Demographic and clinical information for each individual participant is shown in Table 1. Median (interquartile range (IQR)) age was $76(71,80)$ years. Median (IQR) logMAR binocular VA and Pelli-Robson CS were $0.2(0.18,0.40)$ and $1.65(1.35,1.93)$, respectively. Better and worse eye median (IQR) $\log$ MAR VA was $0.26(0.19,0.40)$ and 0.40
$(0.30,0.95)$ respectively. Three patients had early AMD, 16 had intermediate AMD and eight patients had advanced AMD (GA) according to the Beckman Classification [30] in their better-seeing eye. Interviews lasted a median (IQR) of $15 \min (12,21 \mathrm{~min})$.

\section{Impact of AMD}

Data were coded into three overarching themes relating to the experience of dry AMD: diagnosis, impact on everyday life, and coping strategies. The main themes and subthemes are summarised in Fig. 1.

\section{Diagnosis}

Diagnoses initiated from a variety of different care settings; from routine eye examinations with the patient's optometrist, non-routine examination with an optometrist or general practitioner (GP) after noticing problems with vision, or in the emergency room after noticing visual problems (either related or unrelated to AMD):

'I did not have any real difficulties until ... I was driving along a road and I did not realise that it was now in both eyes ... there was a lady halfway across and I couldn't see her because of the blind spot.' (AM1)

'Well it was the optician who pointed it out to me, I wouldn't have known.' (EF1)

'I went for a regular eye test and the optician told me that she had a machine ... and she used it. When I did that, it was diagnosed.' (EF2)

'I'd just simply gone for an eye test just to get new glasses.' (IF10)

'I had a big black floater ... I was frightened about that, I thought I'd got a detached retina... I rang my $G P$ who said go the $A \& E$ and $A \& E$... told me that that was a floater and nothing to worry about but that I had the beginnings of macular degeneration'. (EF3)

'I couldn't understand why I couldn't see clear enough. The optician said you have cataracts and I thought great, because when I went up to see the consultant I expected him to turn round to me and say 
Table 1 Demographic and clinical characteristics of participants

\begin{tabular}{|c|c|c|c|c|c|c|c|}
\hline ID & Gender & AMD stage & Age & Binocular VA & Better eye VA & Worse eye VA & $\mathrm{CS}$ \\
\hline $\mathrm{EF} 1$ & Female & Early & 84 & 0.28 & 0.38 & 0.46 & 1.5 \\
\hline EF2 & Female & Early & 69 & 0.2 & 0.1 & 0.3 & 1.95 \\
\hline EF3 & Female & Early & 77 & 0.18 & 0.18 & 0.3 & 1.65 \\
\hline IF1 & Female & Intermediate & 86 & 0.1 & 0.26 & 0.26 & 1.65 \\
\hline IF14 & Female & Intermediate & 76 & 0.1 & 0.12 & 0.32 & 1.95 \\
\hline IF2 & Female & Intermediate & 74 & 0.24 & 0.22 & 0.86 & 1.5 \\
\hline IF3 & Female & Intermediate & 61 & 0.02 & -0.04 & -0.02 & 1.95 \\
\hline IF4 & Female & Intermediate & 78 & 0.2 & 0.2 & 0.4 & 1.9 \\
\hline IF5 & Female & Intermediate & 74 & 0.2 & 0.2 & 0.26 & 1.95 \\
\hline IF6 & Female & Intermediate & 82 & 0.26 & 0.22 & 1.58 & 1.35 \\
\hline IF6 & Female & Intermediate & 77 & 0.44 & 0.4 & 0.8 & 1.35 \\
\hline IF7 & Female & Intermediate & 81 & 0.44 & 0.44 & 0.46 & 1.95 \\
\hline IF8 & Female & Intermediate & 62 & 0.2 & 0.3 & 0.3 & 1.65 \\
\hline IF9 & Female & Intermediate & 79 & 0.3 & 0.4 & 0.48 & 1.55 \\
\hline IM1 & Male & Intermediate & 70 & 0.1 & 0.06 & 0.1 & 1.95 \\
\hline IF10 & Female & Intermediate & 69 & 0.1 & 0.1 & 0.12 & 1.95 \\
\hline IF11 & Female & Intermediate & 86 & 0.66 & 0.6 & 1.58 & 0.9 \\
\hline $\mathrm{IF} 12$ & Female & Intermediate & 72 & 0.18 & 0.16 & 0.36 & 1.65 \\
\hline IF13 & Female & Intermediate & 76 & 0.16 & 0.2 & 0.32 & 1.8 \\
\hline AM1 & Male & Advanced & 75 & 0.58 & 0.58 & 2 & 0.25 \\
\hline AM2 & Male & Advanced & 77 & 0.2 & 0.3 & 0.34 & 1.65 \\
\hline AF1 & Female & Advanced & 68 & 0.2 & 0.22 & 1.04 & 1.65 \\
\hline AF2 & Female & Advanced & 73 & 0.52 & 0.58 & 1.04 & 0.3 \\
\hline AF3 & Female & Advanced & 70 & 0.56 & 0.6 & 0.92 & 1.2 \\
\hline AM3 & Male & Advanced & 74 & 0.36 & 0.38 & 0.98 & 1.6 \\
\hline AM4 & Male & Advanced & 80 & 0.32 & 0.32 & 0.4 & 0.75 \\
\hline $\mathrm{AF} 4$ & Female & Advanced & 82 & 0.56 & 0.58 & 1.32 & 1.15 \\
\hline
\end{tabular}

$A M D$ age-related macular degeneration, VA $\log$ MAR visual acuity, CS Pelli-Robson log contrast sensitivity

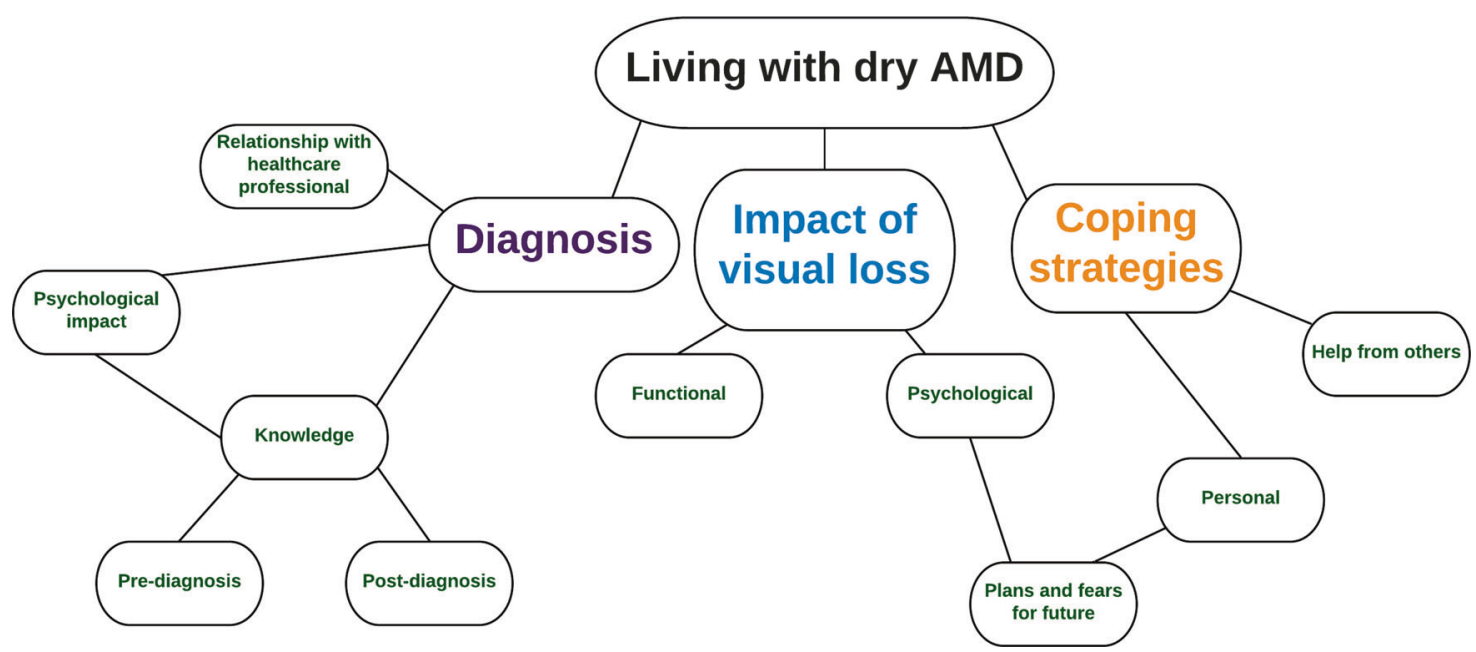

Fig. 1 Diagram showing the main themes and subthemes that emerged from the analysis, and how different categories relate to each other 
you've got cataracts, we'll do something with you. But ... he said to me you have got cataracts but they're not bad ... we wouldn't touch them anyway, because with the macular you let more light in and it will be even worse still for you. So that was a really big worry, that was.' (AM4)

For some patients, diagnosis of a condition that was not yet affecting their vision or daily routine, and that many were unfamiliar with, was not particularly concerning:

'It didn't mean anything to me and since then I've discovered my grandfather and my aunt and uncle ... have all had it.' (AF1)

'That was the start of it so to speak. I had been diagnosed prior to that but as I say I didn't take any notice because it was only in one eye and even that wasn't bad.' (AM1)

Some compared their diagnosis to other medical conditions:

'He tried to explain it to me kind of thing but ... it wasn't affecting me so I wasn't bothered. As far as I was concerned it could have been a cold.' (AM1)

'It's like hearing about Crohn's disease. You know, if you haven't got it or if you don't know anyone who's got it, you don't know what it is. You just-I mean I'm sure I've heard the name of it like I have Crohn's but I hadn't got the least idea what it really does to people.' (AM3)

'That wasn't good news for me to hear that I had got it but on the other hand I was early stages and I wasn't that upset because it wasn't affecting me that much. It was like knowing you're going to get arthritis; I know I'll get arthritis one day I suppose.' (EF3)

Information about AMD was sought from peer support groups (e.g., the Macular Society), from friends or family members with AMD, directly from eyecare professionals, from the Internet and from leaflets available in hospital eye clinics:

'I hot-footed it to Google and found out about it' (EF2)
'I'd remembered years ago [name of friend omitted] saying she had a problem with her eyes, we had children at school together. I said oh is it glaucoma, she said no you won't have heard of it. Then through this I said oh I've got that, it's AMD.' (IF3)

'I discovered that there was a Macular Society and I rang them actually. They were very helpful, I must have been on the phone for nearly an hour with him and then they sent me lots of leaflets and things. Then I found we had a local group so I joined that.' (IF6)

Participants also spoke about the impact of being diagnosed with dry AMD as an untreatable condition:

'At the end of the day he just said you've got dry macular degeneration, end of story and that's how he put it; end of story. So I said to him, what do you mean end of story? He said well that's it, there's nothing we can do, there's no cure for it so there's nothing we can recommend you do, which is quite a big shock.' (AM4)

'I don't hold out a lot of hope although I do have a little spark that maybe something can be done eventually about it.' (IF2)

\section{Impact on everyday life}

Daily activities Several domains of everyday life were reported to be affected by dry AMD. One important everyday task described by some participants was reading:

'Reading is the main thing. Simple things like undoing a package or ... if I need to see detail. Cooking instructions on a jar, reading any sort of labels, going to the shops, seeing the signs over the aisles in a supermarket.' (AF1)

'I just can't read the way that I used to read. I can only just read for a few minutes' (AM2)

Another domain of everyday life identified as important to participants was issues relating to mobility. Some participants recalled falls related to their vision:

'I have to be very, very careful that I don't-actually going up and down stairs. I did have a very bad fall 
some years ago and broke my wrists and that was because I didn't see.' (AM3)

'I don't walk anywhere where there are tree roots or stuff like that because over the last 12 months I've had a couple of falls. So now I walk on paths, recognised paths... if ever the situation arises where I am going to be walking amongst trees, and you do get that situation sometimes, I walk a lot slower and I'm careful where I put my feet.' (AMI)

Others had not experienced falls but found walking particularly worrisome:

'You feel very insecure out of doors. You can't see the edges of pavements. People whizzing past you on bicycles on the pavement are a nightmare... You have this tendency not to panic but to get into a sort of mini panic situation especially when you don't know where you are... Also crossing a road, no matter how used you are, when you get to the other side your heart is racing which is, you know, odd. You can't help tensing up. You feel very vulnerable.' (AF4)

Many current drivers voiced concerns about vision while driving:

'I can still drive, I can still see... now I only drive where I know I'm going to and I know the road. If I have to go say the other side of the river I would not venture... because I couldn't see the signs in time to change lanes or go this way or that way.' (IF13)

'I still drive but I don't drive far, I can't see any signs on the side of the road. I only drive [when] I know where I'm going. I won't drive anywhere else because I'm worried about-I can see driving, I can see the car in front. I probably couldn't read the number plate but I can see the car. I think that concerned me a lot. I used to give people lifts but I don't anymore.' (IF6)

'I don't really like it evening so much now I used to love-that was my favourite time to drive. Now I do find that I'm not so comfortable with that. I prefer to be in daytime.' (IF3)

'I will not pass the driving test anymore, so it means within 6 weeks to 2 months I will not be able to drive anymore. Driving to me has been one of the great joys of my life because I love driving, I love nice cars.' (AM4)

Whilst others had given up driving completely:

'I've missed the car most. You know the feeling when you're going to make something and you realise ah, I haven't got enough milk or I haven't got enough that. Before I could just jump in the car and pop to Sainsbury's or wherever but I haven't got that ability now so I've got to remember everything. I feel there's not much good writing a list because I can't read it so I have to remember it.' (AF3)

Navigating public transport was particularly difficult for some participants:

'When a bus is coming towards me I can't see what number it is until it's almost upon me and it's almost too late to put my hand out. So I found myself stopping busses and it's not been the right number at all. Actually in Hammersmith the last time I was up I got on the wrong bus.' (AF3)

'I nearly got run over by a double-decker bus. It was foggy and the bus was painted pale blue and white and although I was looking towards it I did not see it.' (IF11)

Pastimes, for example, playing bowls, golf, watching television, knitting, sewing, birdwatching, star-gazing, playing music, gardening, eating at restaurants and visiting exhibitions and galleries were all affected by participants' vision loss. One participant described how she was able to track the progression of her dry AMD with her ability to sew:

'I used to make pillow lace. Perhaps 3 years ago, I started a big piece. When I started, it was easy. By the time a year had gone by and I was finishing, I couldn't really see the holes to put the pins in. That was about 2 years ago, 3 years ago. So I've had to stop doing pillow lace making, which is sad. I can't see to thread needles.' (IF7)

Another participant related how she did not want to reveal the extent of her visual loss to her family:

'The other thing that I really love is looking at the stars. ...I've got a son who lives near Ashdown Forest... there's no ambient light. The stars are absolutely fantastic there. I go down with him ... and 
we go out and look at the stars. They say, oh look, there's such and such a constellation, there's another one. I'm saying, oh yes, oh yes, but I can't really see it.' (IF6)

Finally, some participants talked about difficulties with self-care and everyday tasks at home, such as cooking and cleaning:

'Little cleaning jobs at home, my wife will always say, you missed that and I didn't see it.' (AM3)

'I shave with an electric razor... I take the head off, undo the head and then clean it out that way, blow it with a brush and all the rest of it. But I can't do that anymore because I can't see how to undo it and I can't locate it back again because I can't see where they are.' (AM4)

Emotional impact Diagnosis was often a hugely emotional experience and many talked about trying to stay positive directly following their diagnosis:

'Mentally when I was first diagnosed I was very upset about it because I thought I would actually go blind. I know now that I will probably keep my peripheral vision but I hope it doesn't come to that. I find that quite-the thought of having big gaps. I've got small gaps now, I don't really want them to get any bigger [laughs]. I'd find that-if I lost my independence that would be the main thing, it'd cause me a lot of distress. But no doubt I'll try and get round it.' (AF1)

'It was a tremendous psychological shock. I used to write stuff about how I felt, I felt very devastated by it and then gradually you realise it's not happening immediately and you can go on doing everything normally.' (AF2)

'When I was first diagnosed, I was quite devastated because I thought, oh gosh, I don't want to lose my eyesight ... but it hasn't got worse, so I'm lucky really. I know people-and I know people with very little vision at all who get around very well and live good lives and have everything adapted and everything. So it doesn't worry me now, especially my time of life.' (IF6)
Following diagnosis, fear for the future was still an important factor in some people's lives, although most had learnt to manage this:

'My life has not changed at all. If I stop and think about it too much, and what the future's going to be like, it's not very nice. But I'm staying away from those thoughts.' (EF2)

'Like I say, it doesn't bother me per se. I don't think about it. Occasionally, I will think what if I woke up tomorrow and-I don't go on about it all the time, because if I do, I'd probably send myself crazy.' (IF8)

'But I suppose it's underlying anxiety that is going to get worse, that's the sort of emotional impact, yes. But then there are other things I worry about as well so it isn't the first thing I worry about.' (EF3)

'Well I am worried about getting dependent but I have plans to counteract it.' (IF2)

'What's the likelihood of my dry turning into wet? I don't know. I would take an overdose if that went wet' (IF11)

'I was given a sheet, with a little dot in the middle and the grid and I'm supposed to check that every day or every week. Occasionally, I will take it out of the drawer and do it. But I can still see the things moving, little shapes move, or else there are empty spaces. So, like I say, I have that in the drawer. I should have it hanging up somewhere so I can just look at it, but I don't because again, if I did see something that-I suppose what I'm trying to say is I don't want to know if there is something wrong, but I have to know, if you know what I mean.' (IF8)

Worries over driving were of particular concern:

'Well I said about the driving, that's where I shall worry most that it will affect my driving.' (EF3)

'I'm aware of it every day and I worry about it to some extent. I'd hate to have to stop driving.' (AM3) 
Frustration was central to a number of people's experiences, frustration with oneself:

'One of the problems then with AMD is that you find yourself sitting doing nothing, and thinking well, it's frustrating. There's nothing you can do but you need your eyes to do things.' (AM2)

And frustration with others not understanding their condition:

'The better you are at coping with it ... people get fooled into thinking you can see more than you can ... you feel very much at a disadvantage and you cover it up and then you get frustrated because you can't see things ... you get irritated with people fussing over you saying, are you all right? But then you get irritated with them because they don't realise that you can't see. So you're kind of torn between people being very-saying, oh, let me help you, you know, be careful when you know you can cope. But then when they sort of say things like, well you have a look over there, you can see the sign and you know you can't, that's also frustrating.' (AF4)

'When you go to a family get-together and they're producing photographs and they're ignoring you. That's upsetting as well; they're ignoring you. If it was me and you were a sufferer I would be saying we've got a photograph here and it's your grandmother on and her dogs and your grandfather on and he's talking to them so to speak and you feel included then.' (AM1)

'Going out with my family. They all know of course but they don't remember and I have to say hold on please, come and help me, I can't see this. It's frustrating for me and for them.' (IF11)

\section{Coping strategies}

Strategies involving others Support from others helped many people cope with their vision loss, whether family, friends or strangers. Participants talked about becoming more reliant on their partners in both positive and negative ways:

'I'm not looking forward to getting any worse, but I know I'm going to get worse, but as long as I've got the tools to be able to do things I want to do, then fine.
As long as [my wife]'s about, then that will be super.' (AM4)

'All the plans that I had for our family have all gone and it's now all reliant solely on [my wife]. She makes the decisions and takes them here and takes them there and I kind of think I hide in the background and I didn't-don't like that.' (AM1)

Other participants described the support they receive from friends:

'I've got very good friends who always know and they put-I don't have to ask them. They'll just read the menu to me to save me getting my phone, my torch out on my phone which I did quite a lot in restaurants but if I'm with my friends that I know and read the menu to me.' (AF1)

Participants also stressed the value of asking strangers for help where required:

'I had to fly to Belfast last year. When I came to come back I couldn't see my flight. I could see the actual board, I couldn't read so I had to ask one. I find that I have to ask people quite a bit, is that the right place or so I have to ask. As a rule people don't mind so I have to ask more about things.' (AF1)

'I don't mind asking for help in a supermarket. I landed at Reading station once expecting my son and couldn't work my mobile phone and I asked the youngest policeman.' (IF11)

Personal strategies As well as talking about help from others, many participants described ways in which they had personally changed how they go about certain activities. Some found organisation such as sticking to set routines and keeping the home tidy to be useful:

'I suppose I stick to routines. Because if I have a new breakfast cereal or breakfast thing, I've got to look at the recipe on how to heat it up or whatever. That's difficult.' (AF3)

'I'm alright indoors because I know where everything is. I'm a fairly tidy person anyway but I've-no, I know where everything is.' (AF4) 
'When cleaning my teeth I was losing the toothpaste in the sink and I think most was going in the sink rather than on my toothbrush. So then I discovered if I put the toothpaste directly in my mouth-as long as it's only you using the toothpaste it doesn't matterput it directly in my mouth and then brush my teeth... I had wasted so much toothpaste' (AF3)

Slowing down and taking things more carefully helped some participants:

'When I'm cycling I'm no longer reckless. I tend to be slower and look at things harder.' (EF1)

'I wouldn't have thought about pulling out and overtaking, without looking, obviously but now I'll check, check and check before I do it. I don't trust my first glance at anything. So I don't do that very, often, drive that number of miles. I tend to like to drive where I know as well.' (AFI)

'I have to slow down... and I have to pay attention more to what I'm doing... I have to just focus on one thing at a time and see what it is that I'm doing.' (AM2)

Participants talked about how technology had helped with managing their vision loss. Some reported increasing the font or changing contrast or brightness on their Kindles and iPads. Others had bought large screen televisions and computer screens in order to optimise vision.

Many participants reported always carrying a magnifier and/or torch with them. Specific purpose-made low vision aids were discussed:

'Until recently when the person from Somerset Sight came and visited me at home when I was making a drink I would-sounds horrible doesn't it. I'd put my thumb over it like that then I'd know when the water came up and burnt me, then I knew I had enough water in there. He's since given me a little thing that you put on the side of the cup and it tells you when the liquid has come up to the right level.' (AF3)

'I've been to Surrey Sight and they've been very good. I got my watch there and my salt and pepper, put a red thing which is the salt and which is the pepper, things like that, yeah.' (AF2)
Lighting was important to most participants; some described difficulties with bright light, while others talked about their difficulties seeing in dark or dim light:

'Oh well, I like a bright light. I don't-I struggle-I can do it very often but if I'm going to read a book or something, or I'm reading in bed I like the light pretty bright. I don't like, personally, very dim rooms.' (IF1)

'I don't go out at night mainly because of not being able to see very well, kerbs and steps and what-haveyou are difficult. Going to the cinema, I always have to stand at the back for absolutely ages before I can see my way to the seats or anything and that goes for the theatre as well but I go to the cinema quite often, most weeks.' (AF3)

'Probably after about a minute in a shop I might be better, but sometimes I'm just completely blind from out of light into dark and sunlight's terrible, I hate sunlight.' (IF6)

'Sometimes when I just can't pick out the words on something I'll actually have to use a torch... it has to be a good light to see in, though the paradox is that the eye-the light upsets my eye. But so it's a doubleedged sword.' (AM2)

Finally, some participants described head or eye movement strategies that improve their vision:

'When I talk to anybody invariably I'm doing what I'm doing with you; I'm looking over their shoulder. Because then I can see more of their face.' (AM1)

'Well sometimes when I turn my head I can see perhaps a little better but I don't really have all that many problems.' (EF1)

\section{Discussion}

The vast majority of people with AMD are living with the non-neovascular (dry) type. Yet this study was the first, to our knowledge, to qualitatively investigate the patient experience specifically of dry AMD. Many of our participants had relatively good measured visual function; for 
example, more than one half satisfied VA requirements for holding a UK driving license. Yet, in our results, several domains of everyday life were reported to be affected by dry AMD. These domains related to psychological wellbeing as well as ability to perform activities of daily living. Many participants reported feelings of distress at the time of diagnosis, with many reporting a fear of going blind, and a perceived lack of empathy from their eyecare providers. A common theme among participants, particularly those with GA, was a feeling of social isolation due to their visual loss.

A thread running throughout all of the themes was the uniqueness of dry AMD as a chronic, untreatable and slowly progressive condition. Participants described hopelessness and despair following diagnosis and their knowledge that things could only get worse and not better, even at the stages when their vision was not yet significantly affected. This contrasts with other age-related eye conditions, which, whilst causing significant burden to the patient, are treatable. For example, patients with progressing glaucoma described positivity and confidence in their treatment and a feeling of being 'in control' because their condition could be managed [31]. Similarly, patients with nAMD have expressed guarded optimism, with some belief and trust in injections maintaining their vision [32].

The results support our suggestion that the psychological impact of diagnosis of dry AMD differs from that of nAMD, in that many patients are unaware of any visual disturbance prior to diagnosis, and diagnosis is often incidental at a primary eyecare appointment, or secondary eyecare appointment for another condition. Patients must then live with the insurmountable fear of their condition worsening. Studies in the field of glaucoma suggest that fear of disease worsening may have a significant impact on newly diagnosed patients' quality of life, regardless of VA and visual field scores [33, 34]. This is worthy of further investigation in dry AMD and should be the focus of future work.

Some participants expressed discontent with the way their condition had been diagnosed and/or managed by their healthcare professional. This aligns with research conducted previously in AMD (not specific to dry AMD) and low vision as a whole $[5,35,36]$. These findings are in line with Boxell et al. [35] who report information and support provision at the time of diagnosis to be lacking in patients' opinions, despite interventions such as improved guidance for healthcare professionals [33, 34] being put in place since a previous survey. In particular, sufficient information for newly diagnosed patients should be clear and accessible; images widely used online to educate the public about AMD are non-realistic for the majority of individuals with dry AMD [37]; thus, 'hot-footing it to Google' after diagnosis, as one participant related, may do more harm than good.

This study has several key implications for clinical practice. First, there is a need for improved communication between patients and healthcare providers, including written information at time of diagnosis and psychological support after initial diagnosis. Second, key information is also needed for friends and family members, in order to minimise embarrassing and difficult social situations for both parties. Further to this, peer support networks may be beneficial for people at any stage of AMD, but our results suggest that individuals with early AMD may also find visiting peer support groups distressing. Several interviewees said that they were not distressed by their diagnosis immediately as many were asymptomatic, and the implications did not resonate. Going to a support meeting with people with marked visual impairment would cause distress by illustrating the potential pathway of the disease as it progresses. Specific networks for people in the very earliest stages of AMD may be useful. Finally, undiagnosed AMD may present to a variety of primary and secondary healthcare professionals - it is vital that healthcare professionals are equipped with the tools to manage this condition appropriately.

We appreciate that it would be unrealistic to suggest that eyecare professionals provide dedicated in-depth psychological support within the realms of a busy eye clinic. However, evidence suggests that a few simple techniques can be adopted in order to improve the experience of diagnosis of dry AMD. For example, one recent study [38] identified key considerations relevant to breaking bad news in the field of ophthalmology, including recognising and aligning the expectations of patients to those of the practitioner, and managing the impact on the patient of 'extreme sub-specialisation' within ophthalmology, meaning that often patients will be seen by several eyecare professionals with inconsistent communication. Successful strategies for breaking bad news were reported to be use of clear explanations, including giving the patient a 'road map' for the future, taking time with and empathising with the patient. Those working in the eyecare setting ought to undergo regular training on communication skills related to breaking bad news. This may be beneficial in regard to the positive psychological effect on the patients of receiving bad news in a sensitive manner, but also in minimising any detrimental effect on the practitioner responsible for breaking the news [38, 39].

Rehabilitation pathways should be standardised and consistent across the eyecare sector; this information should then be made clear to patients. Evidence suggests that eyecare professionals' views on the importance of rehabilitation services is variable [40]. Moreover, there may be confusion over who is responsible for advising patients about such services [40]. As a result, patients may be left unaware of support networks that are available to them [41]. One solution might be to ensure all individuals with dry AMD are referred to an Eye Clinic Liaison Officer (ECLO), 
whose role includes discussing information about eye conditions, education and employment, providing emotional support to patients and their family members, and referring patients to other relevant support services such as counselling or social services [42, 43].

Our study is the first to investigate the experience of living with dry AMD using qualitative methods. Yet, our study has limitations. All participants were volunteers who responded to a call for participants; it is likely that this has biased the views represented in our study. Furthermore, participants were able to travel to central London for their study visit. Subsequently, we may have underestimated problems with mobility and isolation in the general dry AMD population. Participants were also required to be in relatively good general health with no ocular comorbid conditions - many patients with dry AMD are living with other conditions which may exacerbate problems; this would not have been captured using our study design. In addition, our logMAR VA cut-off of 0.7 would have excluded those with advanced central GA. Moreover, the median binocular VA of our participants of 0.2 (Snellen equivalent of 6/9.5 or 20/32) was relatively 'good'. However, it is well-evidenced in the literature [44] that VA may not be the best measure of an individual's visual function in early and intermediate $\mathrm{AMD}$, and that VA may remain 'good' whilst other measures of visual function (such as dark adaptation) decline. Recall bias may have influenced our results; particularly with respect to recall of healthcare visits as patients' recall of clinical consultations is reported to be poor $[32,33]$. Whilst this may have affected the historical accuracy of the patient reports, the overall message that more needs to be done to improve this experience for the patient remains. Finally, our convenience sample, consisting mostly of female respondents with intermediate AMD, is not likely to be completely representative of a population of people living with the condition.

To conclude, dry AMD has some unique burdens on the patient that may require specific and tailored management strategies. Diagnosis itself, regardless of vision loss, may cause a significant psychological burden related to fear and a noteworthy anxiety about the condition worsening. Furthermore, self-perceived impact on daily life may be considerable even while clinically measured visual function remains relatively good.

\section{Summary}

\section{What was known before}

- Dry AMD is a widely prevalent, gradually progressive condition with no currently available treatment.
- Qualitative research is a useful methodology for investigating the impact of a condition and for shaping future research and practice.

- To date, no studies have qualitatively investigated the impact of dry AMD on the patient.

\section{What this study adds}

- Diagnosis of dry AMD results in significant psychological burden for the patient and many fear 'going blind'.

- Perceived impact on daily life may be considerable whilst measurable visual function remains reasonable. Improved support is needed for patients, both directly following diagnosis and in the longer term.

Acknowledgements The authors would like to thank Dr. Fiona Glen for her support with producing the interview topic guide for this study, and the Macular Society for their invaluable help with recruitment of participants.

Funding This study was funded as part of an unrestricted investigatorinitiated research grant from Roche Products Ltd. UK. The sponsor or funding organisation had no role in the design of the study, collection and analysis of data and decision to publish.

\section{Compliance with ethical standards}

Conflict of interest The authors declare that they have no conflict of interest.

Publisher's note: Springer Nature remains neutral with regard to jurisdictional claims in published maps and institutional affiliations.

Open Access This article is licensed under a Creative Commons Attribution 4.0 International License, which permits use, sharing, adaptation, distribution and reproduction in any medium or format, as long as you give appropriate credit to the original author(s) and the source, provide a link to the Creative Commons license, and indicate if changes were made. The images or other third party material in this article are included in the article's Creative Commons license, unless indicated otherwise in a credit line to the material. If material is not included in the article's Creative Commons license and your intended use is not permitted by statutory regulation or exceeds the permitted use, you will need to obtain permission directly from the copyright holder. To view a copy of this license, visit http://creativecommons. org/licenses/by/4.0/.

\section{References}

1. Varano M, Eter N, Winyard S, Wittrup-Jensen KU, Navarro R, Heraghty J. The emotional and physical impact of wet age-related macular degeneration: findings from the wAMD Patient and Caregiver Survey. Clin Ophthalmol (Auckl, NZ). 2016;10: 257-67.

2. Boyle J, Vukicevic M, Koklanis K, Itsiopoulos C. Experiences of patients undergoing anti-VEGF treatment for neovascular age- 
related macular degeneration: a systematic review. Psychol, Health Med. 2015;20:296-310. 2015/04/03

3. Taylor DJ, Hobby AE, Binns AM, Crabb DP. How does agerelated macular degeneration affect real-world visual ability and quality of life? A systematic review. BMJ open. 2016;6: e011504.

4. Dean S, Mathers JM, Calvert M, Kyte DG, Conroy D, Folkard A, et al. "The patient is speaking": discovering the patient voice in ophthalmology. Br J Ophthalmol. 2017;101:700 https://doi.org/ 10.1136/bjophthalmol-2016-309955

5. Glen FC, Baker H, Crabb DP. A qualitative investigation into patients' views on visual field testing for glaucoma monitoring. BMJ open. 2014;4:e003996.

6. Glen FC, Crabb DP. Living with glaucoma: a qualitative study of functional implications and patients' coping behaviours. BMC Ophthalmol. 2015;15:128.

7. Lacey J, Cate H, Broadway DC. Barriers to adherence with glaucoma medications: a qualitative research study. Eye [Clin Study]. 2008;23:924

8. Kotecha A, Bonstein K, Cable R, Cammack J, Clipston J, Foster P Qualitative investigation of patients' experience of a glaucoma virtual clinic in a specialist ophthalmic hospital in London, UK. BMJ Open. 2015;5. https://doi.org/10.1136/bmjopen-2015009463.

9. Jones RK, Jefferis JM. Is qualitative research under-represented in ophthalmology journals? Eye [Comment]. 2017;31:1117.

10. McCloud C, Khadka J, Gilhotra JS, Pesudovs K. Divergence in the lived experience of people with macular degeneration. Optom Vis Sci. 2014;91:966-74.

11. Burton AE, Shaw RL, Gibson JM. Living together with agerelated macular degeneration: an interpretative phenomenological analysis of sense-making within a dyadic relationship. $\mathrm{J}$ health Psychol. 2015;20:1285-95.

12. Moore LW, Constantino RE, Allen M. Severe visual impairment in older women. West J Nurs Res. 2000;22:571-95.

13. Moore LW, Miller M. Driving strategies used by older adults with macular degeneration: assessing the risks. Appl Nurs Res. 2005;18:110-6.

14. Weaver Moore L, Miller M. Older men's experiences of living with severe visual impairment. J Adv Nurs. 2003;43:10-8.

15. Owsley C, McGwin G Jr, Scilley K, Dreer LE, Bray CR, Mason JO III. Focus groups with persons who have age-related macular degeneration: emotional issues. Rehabil Psychol. 2006;51:23.

16. Cimarolli VR, Boerner K, Brennan-Ing M, Reinhardt JP, Horowitz A. Challenges faced by older adults with vision loss: a qualitative study with implications for rehabilitation. Clin Rehabil. 2012;26:748-57.

17. Stanford P, Waterman H, Russell WB, Harper RA. Psychosocial adjustment in age related macular degeneration. $\mathrm{Br} \mathrm{J}$ Vis Impair. 2009;27:129-46.

18. Kleinschmidt JJ. Older adults' perspectives on their successful adjustment to vision loss. J Vis Impair Blind. 1999;93:69-81.

19. Smith TM. Adaptation to low vision caused by age-related macular degeneration: a case study. J Vis Impair Blind. 2008; 102:725.

20. Wong EY, Guymer RH, Hassell JB, Keeffe JE. The experience of age-related macular degeneration. J Vis Impair Blind. 2004; 98:629-40.

21. Chylack LT, Wolfe JK, Singer DM, Leske MC, Bullimore MA, Bailey IL, et al. The lens opacities classification system III. Arch Ophthalmol. 1993;111:831-6.

22. Brown MM, Brown GC, Sharma S, Smith AF, Landy J. A utility analysis correlation with visual acuity: methodologies and vision in the better and poorer eyes. Int Ophthalmol. 2001;24:123-7.
23. Hirneiss $\mathrm{C}$. The impact of a better-seeing eye and a worse-seeing eye on vision-related quality of life. Clin Ophthalmol (Auckl, NZ). 2014;8:1703-9.

24. Rubin GS, Muñoz B, Bandeen-Roche K, West SK. Monocular versus binocular visual acuity as measures of vision impairment and predictors of visual disability. Invest Ophthalmol Vis Sci. 2000;41:3327-34.

25. Folstein MF, Folstein SE, McHugh PR. Mini-mental state": a practical method for grading the cognitive state of patients for the clinician. J Psychiatr Res. 1975;12:189-98.

26. McKeague C, Margrain TH, Bailey C, Binns AM. Low-level night-time light therapy for age-related macular degeneration (ALight): study protocol for a randomized controlled trial. Trials [J Artic]. 2014;15:246.

27. Margrain TH, Nollett C, Shearn J, Stanford M, Edwards RT, Ryan $\mathrm{B}$, et al. The Depression in Visual Impairment Trial (DEPVIT): trial design and protocol. BMC psychiatry. 2012;12:1.

28. Tong A, Sainsbury P, Craig J. Consolidated criteria for reporting qualitative research (COREQ): a 32-item checklist for interviews and focus groups. Int J Qual Health Care. 2007;19:349-57.

29. Pope C, Ziebland S, Mays N. Analysing qualitative data. BMJ: Br Med J. 2000;320:114-6.

30. Ferris FL, Wilkinson C, Bird A, Chakravarthy U, Chew E, Csaky $\mathrm{K}$, et al. Clinical classification of age-related macular degeneration. Ophthalmology. 2013;120:844-51.

31. Cross V, Shah P, Glynn M, Chidrawar S. ReGAE 5: Can we improve the surgical journey for African-Caribbean patients undergoing glaucoma filtration surgery? Some preliminary findings. Clin Ophthalmol (Auckl, NZ). 2009;3:1-12.

32. McCloud C, Lake S. Understanding the patient's lived experience of neovascular age-related macular degeneration: a qualitative study. Eye [Clin Study]. 2015;29:1561.

33. Jampel HD, Frick KD, Janz NK, Wren PA, Musch DC, Rimal R, et al. Depression and mood indicators in newly diagnosed glaucoma patients. Am J Ophthalmol. 2007;144:238-44. e1

34. Janz NK, Wren PA, Lichter PR, Musch DC, Gillespie BW, Guire KE. Quality of life in newly diagnosed glaucoma patients: The Collaborative Initial Glaucoma Treatment Study. Ophthalmology. 2001;108:887-97.

35. Boxell EM, Amoaku WM, Bradley C. Healthcare experiences of patients with age-related macular degeneration: have things improved? Cross-sectional survey responses of Macular Society members in 2013 compared with 1999. BMJ Open. 2017;7. https://doi.org/10.1136/bmjopen-2016-012790.

36. Burton AE, Shaw RL, Gibson JM. 'I'd like to know what causes it, you know, anything I've done?' Are we meeting the information and support needs of patients with macular degeneration? A qualitative study. BMJ Open. 2013;3 https://doi.org/10.1136/ bmjopen-2013-003306.

37. Taylor DJ, Edwards LA, Binns AM, Crabb DP. Seeing it differently: self-reported description of vision loss in dry agerelated macular degeneration. Ophthalmic Physiol Opt. 2017;38:98-105.

38. Mishra A, Browning D, Haviland MJ, Jackson ML, Luff D, Meyer EC, et al. Communication skills training in ophthalmology: results of a needs assessment and pilot training program. J Surg Educ. 2018;75:417-26.

39. Martin EB, Mazzola NM, Brandano J, Luff D, Zurakowski D, Meyer EC. Clinicians' recognition and management of emotions during difficult healthcare conversations. Patient Educ Couns. 2015;98:1248-54.

40. Gillespie-Gallery H, Conway ML, Subramanian A. Are rehabilitation services for patients in UK eye clinics adequate? A survey of eye care professionals. Eye [Clin Study]. 2012;26:1302.

41. Hodge S, Thetford C, Knox P, Robinson J. Finding your own way around: Experiences of health and social care provision for people 
with a visual impairment in the United Kingdom. Br J Vis Impair. 2015;33:200-11.

42. Subramanian A, Gallery HG, Conway ML. The role of the Eye Cinic Liaison Officer (ECLO)-A diary study. Investigative Ophthalmology \& Visual Science. 2012;53:4407.
43. Norwell C, Hiles C. Why every hospital should have an eye clinic liaison officer. Int Congr Ser. 2005; 1282:226-9.

44. Hogg RE, Chakravarthy U. Visual function and dysfunction in early and late age-related maculopathy. Prog Retin Eye Res [Rev]. 2006;25:249-76. 